\title{
Towards an Understanding of the Political Economy of the PPCR
}

\author{
Fran Seballos and Sönke Kreft*
}

\begin{abstract}
While an analysis of the Pilot Program for Climate Resilience (PPCR) is inseparable from wider discussion on adaptation finance, this article primarily focuses on the drivers and ideologies that shaped the PPCR governance and delivery structures. The core narrative of mainstreaming adaptation into development through a process of government-centred policy reform challenges many principles of the UNFCCC process. Utilising the structures of international financing institutions as implementing agencies, heightens this tension. The central idea of mainstreaming adaptation through climate-proofing existing development initiatives utilises the standard economic growth narrative. This climate 'add-on' approach to development allows the World Bank Group and other multilateral development banks (MDBs) to claim a space in managing future climate finance flows. This drive by the Bank plays out in the exclusivity of the design process for the PPCR and through the implementation modalities, which severely curtail opportunities for multi-stakeholder dialogue and thus the potential for development of broad country ownership of programmes.
\end{abstract}

\section{Introduction}

Since the announcement of an 'Adaptation Pilot' as part of the Climate Investment Funds (CIFs), the Pilot Program for Climate Resilience

(PPCR), has been dogged by criticism and continues to attract critique on both international and national scales. The contention around the role of the World Bank and multilateral development banks (MDBs) in climate finance, the use of loans and the modalities of the PPCR governance and delivery structures are framed by ongoing negotiations under the United Nations Framework Convention on Climate Change (UNFCGG), on adaptation finance. Despite the criticisms and ongoing tension however, the funding is welcomed in many of the participating countries and aspects of the PPCR and the wider CIFs have gathered support among academics, civil society organisations (CSOs), donors and developing country governments.

Approved in November 2008, the PPCR was the first operational programme under the Strategic Climate Fund (SCF) - one of two key programmes in the GIFs held by the World Bank (the other being the Clean Technology Fund). The CIFs were created to 'bridge the financing and learning gap' prior to agreements on postKyoto financing (Tan 2008). They are currently funded by 12 countries, of which eight have pledged a total of US\$972 million to the PPCR. PPGR funds are made up in the majority as grant funding, but with concessional loan funds from the UK's International Environmental Transformation Fund (IETF) - the single biggest contribution being US $\$ 358$ million (Table 1).

Funds, in the form of grants and loans, are intended to blend with existing development funds to enhance resilience, but are also available to fund technical assistance. The technical assistance element is primarily aimed at improving the country-level capacity necessary to achieve the overarching transformative goal of the PPCR - mainstreaming adaptation into development planning. Central to the design and investment programmes of the PPCR is the provision of funds to cover the 'add-on' costs to development programmes, thereby providing the incentive to achieve 'climate resilient development'. However, the programme contains a sunset clause, which means it is subject to closure on the arrival of new UNFCGG post-2012 finance architecture. 


\begin{tabular}{lll}
\hline Table 1 Pledges to PPCR as of September 2010 & \\
\hline PPCR donor & Type & Pledge in US\$ million \\
\hline Australia & Grant & 39 \\
Canada & Grant & 84 \\
Demark & Grant & 14 \\
Germany & Grant & 68 \\
Japan & Grant & 111 \\
Norway & Grant & 8 \\
UK & Capital & 358 \\
USA & Grant & 290 \\
Total & & 972 \\
\hline
\end{tabular}

Source CIF (2010).

This article explores the political economy of the PPCR at the international level from conceptualisation to implementation. While it touches on many of the issues raised over the past three years, it primarily seeks to address a gap in understanding of both the drivers and ideologies that frame the PPCR at the international level and which inform its operation. The article provides a framing analysis within which country case studies can be situated (see Shankland and Chambote; Ayers et al.; Alam et al., all in this IDS Bulletin) as well as drawing out lessons to inform the debates on climate finance in the near future.

Research for the article draws on interviews with key actors engaged in the PPCR process, including representatives from the World Bank, donors, the expert group and observer organisations. Primary data was combined with reviews of the programme documentation and a review of relevant wider literature.

\section{Ideological drivers of the PPCR - meeting whose agenda? \\ 2.1 Governments and growth}

The PPCR emerged from a political understanding of the urgency to expedite climate action expressed by leading donors in the G8. The three-year Gleneagles Plan of Action on Climate Change, Clean Energy and Sustainable Development of 2005 explicitly requests the World Bank and other MDBs to engage in financing the transition to clean energy and to develop and implement climate risk management for their and others' development investment portfolios (G8 2005). The G8 communiqués in Gleneagles (2005), St Petersburg (2006) and Heiligendamm (2007) featured elements of climate policy, albeit heavily dominated by mitigation issues. Mitigation and emissions reduction was at the heart of donor attention - as reflected by expert insights and the general level of donor money apportioned to different parts of the CIFs ${ }^{1}$ - and this was reflected in the design process. The CIF's focus on mitigation, rather than adaptation activities in developing countries, can be seen as a reflection of the G8 countries' national interest.

Despite this domination, a number of key underlying ideologies also framed the PPCR and informed its institutional set-up. At the core of the PPCR is the notion that adaptation and development are closely interrelated processes, where general 'good' development progress helps increase the capacity to adapt to climate change and reduce vulnerability to its impacts (Stern 2007). Climate change is regarded as an instrumental threat to the achievement of development objectives and the PPCR seeks to be 'transformational' in its policy reform agenda, which in turn aims to internalise the challenge of climate change in development planning. With this approach, PPCR funds can be legitimately channelled to existing development programmes in an attempt to manage any negative climate impacts on donor investments without challenging the basic trajectory of economic growth embodied in standard development practice (Paterson 2009). 
Approaches to mainstreaming adaptation which clearly play out in the PPGR context reflect a donor-led conceptualisation that promotes mainstreaming through embedding adaptation in government development planning processes and through 'Encouraging a ministry with a broad mandate, such as planning or finance, to be fully involved in mainstreaming adaptation' (AfDB 2003: XI). The targeting of developing country finance and planning ministries - who commonly had little or no prior engagement with climate change - is a key strategy in the PPCR's policy reform agenda. In its vision of transformation, the PPCR seeks to develop the institutional capacity for longer-term 'climate resilient development' through what can be seen as a government-centred process. This 'whole government' approach is articulated in the recent OECD policy guidance on integrating adaptation into development cooperation (OECD 2009). However, the central focus on government actors may miss a wide range of sectoral and local knowledge and expertise at the country level.

\subsection{Reputation and responsibility}

The mainstreaming approach underpins the dedication of a new multilateral 'adaptation' fund with an institutional set-up offering a comparative advantage in development catalysis for this purpose. Although converging drivers support the need for mainstreaming adaptation into development, multiple drivers identified by Gupta (2009: 209) include the potential that 'the governments of the leading economies are seeing the need to converge the two debates as a way to make their meagre resources go a longer way'. The potential that focusing on mainstreaming as a predominant adaptation activity could be a way for developed countries to bypass obligations of the UNFCGG is refuted by Ayers and Huq (2008), who stress that 'while there is clearly a role for development institutions in enhancing adaptive capacity, responsibility for adaptation does not lie with these institutions'.

Responsibility for adaptation funding is articulated through the principle of historical and differentiated responsibility explicit in the UNFCCG agreements, which provides for new and additional adaptation funding to be made available by developed countries.

Much of the political controversy around the CIFs as a whole, but the PPCR in particular, centres on the use of the World Bank and MDBs as a channel for climate finance as opposed to UN-based funds (see Bretton Woods 2008; Dahle Huse 2008; Tan 2008; Marston 2010; Müller 2010). The World Bank and the MDBs, predominantly lending institutions, are associated with being a vehicle for developed country interests, ${ }^{2}$ and contrast starkly with the governance structure of the Adaptation Fund established by the Kyoto Protocol which placed a developing country majority on the Adaptation Fund Board (AFB) after years of contention (see Harmeling and Kaloga, this IDS Bulletin).

In addition, the track record and future of the World Bank and MDB portfolio in contributing to environmental degradation and climate change through unsustainable development pathways has been a central factor in the ongoing debate. This notion of inappropriate investment from the World Bank Group was, and still is, central to a number of arguments from the South and from global civil society (see Dahle Huse 2008; Tan 2008; IBON International 2009; Müller and Winkler 2008) but has also been recognised by donors. Some see the establishment of the CIF as a response to this critique and a positive step towards greening the MDB portfolio and correcting its emission driving and maladaptive investments. This was also the reason cited for why the US senate and congress did not approve the first appropriation for the CIF in 2009. ${ }^{3}$

\section{Negotiating the PPCR - degrees of engagement? \\ 3.1 Room for review}

In early 2008, leaders from the UK, the USA and Japan announced their intention to 'establish a multibillion-dollar fund...' that '.. will boost the World Bank's ability to help developing countries tackle climate change' (Paulson et al. 2008).

Following early discussions with the three leading donors and the regional development banks, a 'zero draft' document for the CIFs was prepared by the Bank (World Bank 2008a). The draft was strongly framed by a concept of transformation, proposing two core mitigation funds, an adaptation pilot and the potential for further transformative funds to 'provide concessional finance for policy reforms and investments that achieve development goals through a transition to a low carbon development path and climate resilient economy'. 
The consultation draft was to form the basis for consultation with wider 'interested parties' identified as potential donors, the private sector and the pre-designated implementing agencies (MDBs and World Bank Group) who were targeted to engage in a six-month process for designing, approving and launching the funds. The article, leaked towards the end of January 2008 , created a tidal wave of criticism captured by Müller and Winkler (2008), who described the PPCR as '.. an unnecessary proliferation of adaptation funds under a governance structure wholly unacceptable to the large majority of countries in the world'.

The specific criticisms of the PPCR reflected heavily on the notion of equity, transparency and access in managing and delivering climate funds as advocated by civil society (see ActionAid 2007) and developing countries through the UNFCGC (see Harmeling and Kaloga, this IDS Bulletin). The zero draft had not included modalities for developing country representation in decisionmaking, which was widely condemned by civil society and academia (Müller and Winkler 2008), as well as important donors involved in the process ${ }^{4}$ and corrected thereafter. Other central critiques focused on:

- The role of loans in potentially increasing the debt burden of vulnerable countries;

- The potential for an 'Adaptation Pilot' to undermine the UNFCGC Adaptation Fund;

- The lack of harmonisation with existing climate change initiatives at country level;

- The dominance of the World Bank Group (WBG) in the design process and proposed implementation modalities;

- The weak engagement with civil society and other actors.

The dissent led to a series of changes in the proposal for an 'Adaptation Pilot Fund' that were embodied in the 25 March 2008 discussion draft for the Pilot Program for Climate Resilience, which emerged from the 4-5 March donor meeting in Paris (World Bank 2008b).

Formal statements issued from the climate negotiations in Bangkok, April 2008, from the G77 (Group of 77/China 2008) and a letter signed by both Southern and Northern NGOs (Third World Network et al. 2008), contributed to the critique of the proposed modalities and the exclusive design process. Finally, a wider meeting of 40 civil society, developing country and donor representatives was convened in Potsdam, Germany in May 2008. This meeting, cast by the World Bank interviewee as the 'core meeting for PPCR formulation', approved the modified PPCR as a channel for funds to mainstream adaptation into development programmes. The funds were formally announced at the G8 meeting in Hokkaido, Japan in July 2008.

\subsection{Cause for concern}

Criticism remains around the speed at which the funds were negotiated and established and the lack of opportunity for influential engagement with civil society, particularly those from the global South. However, a set of key controversial proposals remained unchanged in the design of the PPCR. Key among these relates to the implementation elements of the PPCR, which were tied into MDB delivery structures from the outset. The use of implementation intermediaries not only goes against calls for direct access to climate finance, both for countries and civil society, but raised three significant concerns:

- The potential for implementing agencies to direct the use of the funds in ways which benefit their own institutions;

- The opportunities for conditions to be imposed through interventions in national policy;

- The potential for undermining national ownership of the PPCR process (Dahle Huse 2008).

In addition, the inclusion of a sunset clause into the PPCR may create an imperative to spend within a given timeframe, potentially favouring programmes and projects where vested interests lie (see UNDP 2010) - as much a risk for country-led processes as for intermediaries.

A second set of issues focused on the targeting of a new set of players in climate finance and adaptation planning at country level, adding to the controversy around the development of new processes outside the UNFCCG structures. UNFCCG-led adaptation processes in developing countries, including the implementation of National Adaptation Programmes of Action (NAPAs), are usually pursued by line-ministries responsible for UNFCGC matters, often the Ministry of Environment, although these are viewed by some as being a bottle-neck to achieve transformational change 
(Fankhäuser and Schmidt-Traub 2010). The PPCR advocates mainstreaming through ministries of finance and planning, who are often new national players in adaptation activities with little or no capacity for climate change planning, with poor understanding of the baseline of existing climate change adaptation activities and not acquainted with the principles and modalities of the UNFCCG. The focus on a delivery relationship with these ministries ignores the historic foci of climate change activity at government level, missing the opportunity to build on existing expertise and plans.

From the perspective of the PPCR programme, the need to build capacity in these ministries is central to the policy reform agenda required to enable the transformative process of mainstreaming adaptation into development planning and policy. However, in some developing countries, the aim to work with new actors opens up rifts at the national level - equal to those internationally - with the need, challenged by some, to delineate between adaptation and 'climate resilient development' (see Alam et al.; Ayers et al., both in this IDS Bulletin).

Centring climate finance delivery in structures outside the country architecture retains power in spaces beyond the influence of the country government and civil society actors. This may shape country level planning and prioritisation to deliver concepts and ideas that are articulated at the global level, without effectively taking into account the local specificities, expertise or existing operational modes (see Tanner and Allouche, this IDS Bulletin).

\section{Implementation implications - rolling out the PPCR}

\subsection{Dynamics of decision-making}

The 'organisational meeting' of the PPCR subcommittee in October 2008 was composed of representatives from four donor countries, five developing countries, the AFB and international financial institutions (IFIs). The selection process of the early developing country representatives on the sub-committee exclusively involved consultation between World Bank executive directors and MDB representatives. As four out of five countries selected via this closed process were invited to participate as pilot countries in the PPCR, the nature of the identification and selection of the invited countries was brought sharply into question.
However, interviews indicate that in practice, the selection of recipient countries holds little real controversy. The identification process is widely recognised as a top-down, science-driven process rather than more demand-led; a process which itself may not lead to prioritisation (see Klein and Möhner; Harmeling and Kaloga, both in this IDS Bulletin). An expert group was tasked with identifying countries based on those eligible for official development assistance (according to OECD/DAC guidelines) and who have active MDB lending programmes or are in dialogue with the MDB (CIF 2008). It was indicated that priority was to go to the highly vulnerable least developed countries, and small island developing states (SIDS). They also consider the following core issues:

- Vulnerability criteria (to climate risk);

- Preparedness and ability to move toward climate resilient development plans;

- Distribution across the regions and hazard types.

The expert group grounded its selection process in the first and third elements, focusing on vulnerability and distribution spatially (according to World Bank-defined regions) and by hazard in order to support the PPCR mandate for lesson learning to scale-up future investments.

According to interview respondents, despite the mandate of the PPCR sub-committee, management and liaison with the expert group was led by the World Bank and the MDBs, with little or no direct communication with the subcommittee. In practice, the final selection process primarily followed the recommendations of the expert group except in four key areas:

(1) the replacement of Mauritania with Yemen;

(2) the dissolution of South-east Asia as a region and the resultant selection of Cambodia only; (3) the inclusion of Mozambique, and (4) changes to the country selection within the Caribbean and South Pacific regional programmes.

Changes were primarily driven by the World Bank and MDBs and are deemed to have been related to the lack of capacity for MDB operations in Mauritania, a need to represent the World Bank's Middle East and North Africa (MENA) region, which embraced Yemen, and the recognition of the need for greater Africa representation leading to the subsequent review 


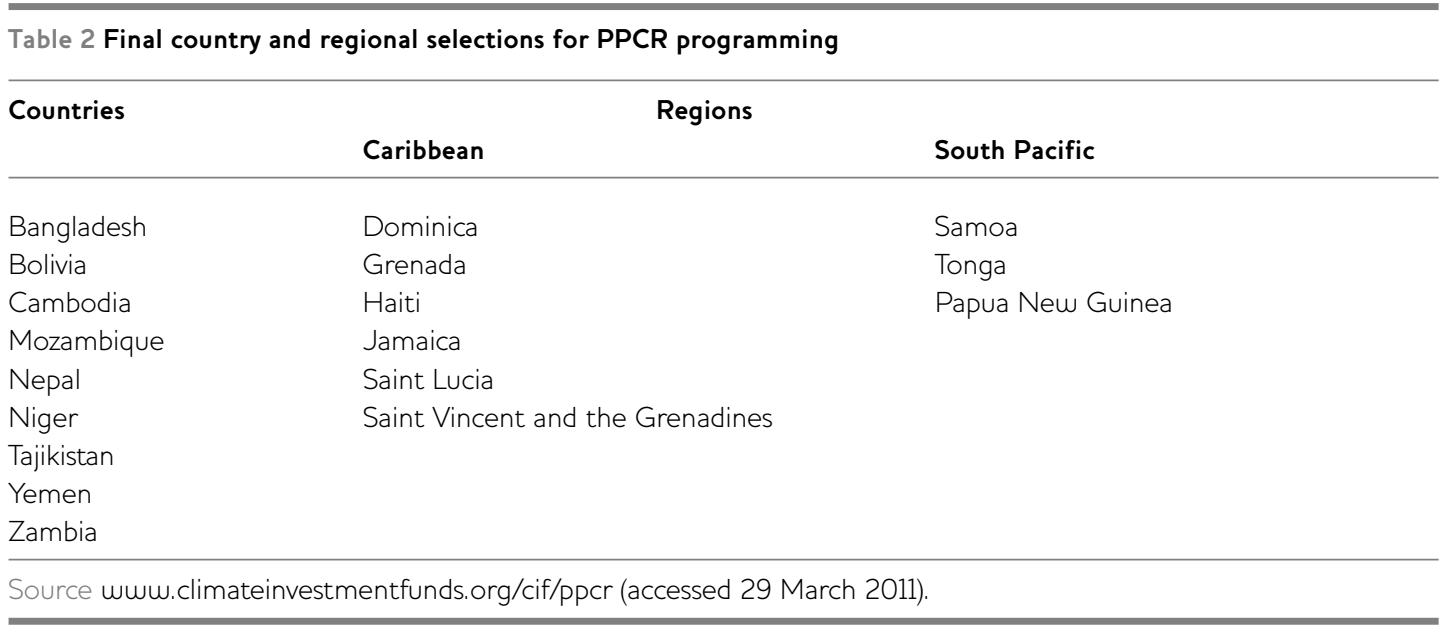

of least developed countries (LDGs) in Africa and the inclusion of Mozambique. Evidence from key actors suggests that Yemen, already on the sub-committee, used their position to lobby for selection as representative of the MENA region, while donor agency country staff in Mozambique lobbied internally for inclusion, which led to the review of the African LDCs (see Shankland and Chambote, this IDS Bulletin). Final country and regional selections for PPCR programming are shown in Table 2.

Once selected, the representation of developing countries on the sub-committee was changed to align with the recipient countries. However, there remains a wider concern from developing countries over lack of equity in the governance structures, with recipient country representatives constrained by the pre-existing PPCR modalities of operation. Although the 'active' observer role at international level is seen as progressive in terms of transparency and accountability, this concern for improved equity extends to a call for an active civil society role in decision-making. Despite amended governance structures, research for this article suggests that the PPCR is still perceived as top-down in its delivery.

\subsection{Conditionality and capture}

In the early stages of negotiation many actors raised concerns around the potential for attaching (political) conditionalities to the PPCR but to date, these concerns are unfounded. Although in some areas the policy reform agenda has been construed as conditional, many countries have channelled PPCR capacity funds towards strengthening existing or emerging structures.
However, there remain a number of areas where the opportunity for donor and implementing agency influence and rent-seeking still remains controversial. The greatest concern centres on the role of the MDBs as implementers and the potential for driving implementation of the PPCR towards their existing programmes. The PPCR mission guidelines issued to MDBs (CIF 2009) gives the MDBs, at a minimum, equal stature with the PPCR country governments. In many cases, although certainly not all (for Nepal see Ayers $e t$ al., this IDS Bulletin) a lack of country level capacity has meant that the national government appoints the MDB as de facto leader of the process.

While the guidelines for missions and Phase I delivery refer to engagement with civil society and NGOs, the emphasis is on dialogue with other climate finance donors/development partners and UN agencies to identify and promote the necessary opportunities for cofinance during Phase II. The rapid planning process - Phase I was to be completed within 18 months - prioritised partnerships between recipient country governments and external agencies. This focus on external engagement and leadership seriously challenges the conception of the PPCR as an inclusive 'country-driven' process, instead sidelining the role and voice of civil society and other expert actors in the planning and delivery process. Interviews for this article suggest that the role of CSOs and affected stakeholders is limited to contributing knowledge and engaging in strategic areas of focus (e.g. awareness raising). This arms-length approach to stakeholder ownership at the country level means CSOs have little access to decision-making processes and vulnerable groups 
are rendered objects rather than citizens in a change process. $^{5}$

Finally, the modalities of the PPCR, which means that funds are disbursed through the IFIs, means that a proportion of the available money is diverted to cover costs incurred in the management of the project cycle (CIF July 2009). While reports suggested a proposed 'fee of $\$ 350,000$ be charged for each investment project... approximately $40 \%$ more than the standard MDB project fee' (Marston 2010: 1), the PPCR subcommittee have now agreed to approve costs on a programme-by-programme basis (CIF Nov 2010). Such proposals, emerging during the implementation phase, underpin and reinforce the controversy that donors have chosen to disburse their funds through the World Bank and MDBs. The non-negotiable channelling of PPCR funds through MDBs implies a driving rationale and logic for a World Bank Group role in climate finance.

\section{Conclusion}

Many observers interpret the World Bank initiative to launch the CIFs, along with its overarching Strategic Framework on Climate Change and Development (SFCCD), as a move to position the institution more widely in climate finance. The establishment and management of the CIFs indicate a shift in the World Bank away from ring-fenced project finance to become a platform for pooled resources (see Alexander 2010). The introduction of loans into the climate finance sphere, supported by recent advocacy from the $\mathrm{EU}^{6}$ to extend the role of loans, generates a strong rationale for a lending institution to take a central role in climate finance. The core idea of mainstreaming adaptation into development also embodied in the SFCGD maps out a continued role for the World Bank in the future of climate finance.

The CIFs and the PPCR have paved the way for a longer-term shift in climate finance sources and delivery mechanisms which establish a longerterm role for the World Bank and the MDBs in both financing and implementing mainstreamed adaptation. These forms of finance shift the landscape for action on the ground and further frustrate the ability of those most vulnerable to climate change impacts to shape future adaptation funding flows.

The set-up of the CIFs within the World Bank as a fund designed to engage MDBs reflects a top- down and donor-driven process. The challenge to deliver the PPCR within the timeframe imposed by its sunset clause means that a focus on speed and results has led to a lack of depth in certain areas such as inclusive multi-stakeholder ownership. This has been evident at both the negotiation phase and through the implementing modalities. This weak inclusion of developing countries and civil society stakeholders in the early phase design process limited their input and led to a programme and structure more in tune with the donor and MDB agenda than one which seeks to respond to needs of the most vulnerable and establish true country ownership.

Donors had a role to play at the international level of the PPCR negotiations and were significant in supporting change in the World Bank zero draft. However, the overwhelming power has been retained in the hands of the World Bank and the MDBs both through the design phase and the early implementation at the international level. At country level, donors see themselves as having only little opportunity to influence the negotiation or implementation of the Strategic Program for Climate Resilience (SPCR). It is at the country level that the emphasis on the MDBs as implementing institutions clearly shapes the direction of PPCR delivery.

A political economy analysis of the PPGR points to the need for broader engagement of vulnerable countries and Southern civil society in the design process of global adaptation funding. It highlights the need for clarity between general climate resilience in development processes and standalone adaptation. It also indicates the need for greater harmonisation through a global alignment of climate finance mechanisms to promote and achieve climate adaptation that identifies and enables the most vulnerable to adapt.

Multi-stakeholder engagement grounded in country-level realities can help to identify and build on existing capacities at the national level. This can help to improve the efficiency of disbursing climate finance and to extend its reach and response to those who are most vulnerable. This echoes the calls for the Green Climate Fund announced in Cancun to recognise wider sector engagement in the design phase of the funds as key to avoiding the 'risk of suboptimal outcomes' (Müller 2011: 2). It also points to the need for increasing accountability 
and engagement at the national level around the processes of negotiating, identifying and prioritising investment opportunities by strengthening the role for civil society in decision-making processes. Developing

\section{Notes}

* Research for this article was carried out through the Political Economy of Low Carbon Climate Resilient Development project, coordinated by IDS and funded by the UK Department for International Development (DFID). The views expressed here are the views of the authors and do not represent the views or policies of IDS, DFID, or the UK government.

1 Many interviewees noted that the bulk of attention was with the mitigation fund. It was mainly the UK championing the adaptation issue within the CIFs. The general bias towards mitigation is also signalled by the level of donor pledges between the Clean Technology Fund (US\$4.4bn) and PPCR (US\$0.97bn) (as of October 2010). See http://en.g8russia.ru/docs/ 25.html and www.g-8.de/Content/EN/Artikel/ g8-summit/ anlagen/chairs-summary,template $\overline{\mathrm{Id}}=$ raw, property $=$ publication File.pdf/chairssummary.pdf (accessed 8 March 2011).

2 'We invest in the World Bank and the regional development banks because they provide strong, effective and highly leveraged means to

\section{References}

ActionAid (2007) Compensating for Climate Change: Principles and Lessons for Equitable Adaptation Funding, ActionAid Discussion Paper

AfDB (African Development Bank); Asian Development Bank; Department for International Development; DirectorateGeneral for International Cooperation: the Netherlands; Directorate General for Development: European Commission; Federal Ministry for Economic Cooperation and Development: Germany; Organisation for Economic Co-operation and Development; United Nations Development Programme; United Nations Environment Programme; World Bank (2003) Poverty and Climate Change: Reducing the Vulnerability of the Poor Through Adaptation, Washington DC: World Bank, http://ec.europa.eu/development/icenter/ repository/env_cc_varg_poverty_and_climate_ change_en.pdf (accessed 18 January 2011)

Alexander, N. (2010) 'The World Bank Reboots: Sweeping Investment Lending Reforms in the negotiation and decision-making spaces that embrace a range of actors provides the opportunity to navigate a multitude of ideologies and lead towards a more balanced delivery and reach of climate finance.

advance global prosperity while also promoting core American interests and values', Timothy Geitner, written Testimony before the House Committee on Appropriations, March 2010.

3 www.climatefundsupdate.org

4 For example, minutes from a meeting between the UK's DFID and the UK INGO sector reflect the desire for the UK to distance itself from the consultation draft, www.bond.org.uk/data/files/resources/180/ 8april08_dfid_ppcr_minutes.doc (accessed 29 March 2011).

5 This is an inherent trade-off also existing in the aid effectiveness debate, where the creation of dedicated funds including in country decision-making based on affected groups runs contrary to the call of the Paris Declaration to reduce 'fragmentation' of development assistance.

6 Guardian article: 'Row Over EU Climate Loans Policy', 1 December, www.guardian.co.uk/ environment/2010/dec/01/cancun-climatechange-conference-loans (accessed 29 March 2011).

Works', Heinrich Böll Foundation North America, www.boell.org (accessed 1 January 2011)

Ayers, J. and Huq, S. (2008) Supporting Adaptation to Climate Change: What Role for Official

Development Assistance?, London: International Institute for Environment and Development, www.iied.org/ climate-change/key-issues/ evaluating-adaptation/ supporting-adaptationclimate-change-what-role-for-officialdevelopment-assistan (accessed 1 February 2011)

Bretton Woods (2008) World Bank Climate Finds: 'A Huge Leap Backwards', www.brettonwoodsproject.org/art-560997 (accessed 1 February 2011)

CIF (2010) Trustee Report on the Financial Status of the SCF, Report SCF/TFC.5/4, Washington DC: Climate Investment Funds, www.climateinvestmentfunds.org/cif/sites/ climateinvestmentfunds.org/files/SCF\%204\% 20Trustee\%20Report\%20on\%20financial\%20 status $\% 20$ of $\% 20$ the $\% 20$ SCF\%20march\% 202010.pdf (accessed 31 February 2011) 
CIF (2009) Guidelines for Joint Missions to Design PPCR Pilot Programmes (Phase 1), Washington DC: Climate Investment Funds, www.climateinvestmentfunds.org/cif/sites/ climateinvestmentfunds.org/files/PPCR_joint _mission_guidelines_final.pdf (accessed 1 February 2011)

CIF (2008) The Pilot Program for Climate Resilience Under the Strategic Climate Fund, Washington DC: Climate Investment Funds, www.climateinvestmentfunds.org/cif/sites/ climateinvestmentfunds.org/files/SCF_TFG_ Decision_PPCR_Governance_Jan_27_2009.pdf (accessed 1 February 2011)

Dahle Huse, M. (2008) 'The World Bank's Climate Change Agenda: Bridging the Gaps or Widening the North-South Divide?', in Financing the Cost of Climate Change: Two Perspectives on Who, What and How, Norwegian Forum for Environment and Development

Fankhäuser, S. and Schmidt-Traub, G. (2010) From Adaptation to Climate-resilient Development: The Costs of Climate-proofing the Millennium Development Goals in Africa, Grantham Research Institute on Climate Change and the Environment, www.cccep.ac.uk (accessed 1 February 2011)

Group of Eight (G8) (2005) Gleneagles Plan of Action Climate Change, Clean Energy and Sustainable Development, Gleneagles, Scotland Group of G77/China (G77/China) (2008) 'Statement at AWG-LCA 1 and AWG-KP 5 Bangkok', Earth Negotiation Bulletin 361.12

Gupta, J. (2009) 'Climate Change and Development Cooperation: Trends and Questions', Current Opinion in Environmental Sustainability 2.1: 207-13

IBON International (2009) The World Bank and Climate Change Finance: A View from the South, IBON Policy Brief Series, Manila: IBON International

Marston, A. (2010) World Bank: Access of Impediment to Climate Finance?, Bretton Woods Project, www.brettonwoodsproject.org/doc/env/ WBaccessorimpediment.pdf (accessed 1 February 2011)

Müller, B. (2011) Time to Roll Up the Sleeves - Even Higher! Longer-term Climate Finance after Cancun, Oxford: Oxford Institute for Energy Studies

Müller, B. (2010) No Trust without Respect: Adaptation Quick Start Funding at the Cross Roads, Oxford: Oxford Institute for Energy Studies

Müller B. and Winkler, H. (2008) One Step Forward, Two Steps Back? The Governance of the
World Bank Climate Investment Funds, Oxford: Oxford Institute for Energy Studies, www.oxfordenergy.org (accessed 1 January 2011)

OECD (2009) Integrating Climate Change Adaptation into Development Co-operation, Paris: Organisation for Economic Co-operation and Development

Paterson, M. (2009) 'Global Governance for Sustainable Capitalism? The Political Economy of Global Environmental Governance', in W.N. Adger and A. Jordan (eds), Governing Sustainability, Cambridge: Cambridge University Press

Paulson, H.; Darling, A. and Nukaga, F. (2008) 'Financial Bridge from Dirty to Clean', Financial Times, 7 February

Stern, N. (2007) The Economics of Climate Change: The Stern Review, Cambridge: Cambridge University Press

Tan, C. (2008) 'No Additionality, New Conditionality: A Critique of the World Bank's Proposed Climate Investment Funds', Third World Network, www.foe.org (accessed 20 December 2010)

Third World Network; Friends of the Earth International; Oxfam International; Greenpeace International; Oil Change International; Christian Aid; Bretton Woods Project; Norwegian Church Aid; Birdlife International; Consumers Association of Penang; International Forum on Indonesian Development; Indonesian Society for Social Transformation; Konphalindo; Bali Collaboration on Climate Change; Sustainable Energy and Economy Network US; Ecologistas en Accion; Germanwatch; International Forum on Globalization; International Rivers Network; Global Environment Centre Malaysia; Red Ambiental Loretana; Mexican Action Network on Free Trade; Centre for Encounter and Active Non-Violence; World Economy, Ecology and Development, Germany (2008) Letter to Governments and the World Bank from Civil Society Organisations, www.twnside.org.sg (accessed 20 December 2010)

UNDP (2010) Staying on Track: Tackling Corruption Risks in Climate Change, New York: United Nations Development Programme

World Bank (2008a) 'Consultation draft on Climate Investment Funds', 22 January

World Bank (2008b) 'Discussion draft: Pilot Program for Climate Resilience', 25 March 